\title{
Influência da variação lingüística e da consciência morfossintática no desempenho em leitura e escrita
}

\author{
Sandra Regina Kirchner Guimarães \\ Universidade Federal do Paraná
}

\begin{abstract}
RESUMO
O objetivo deste estudo foi investigar a influência da variação lingüística e da consciência morfossintática nas diferenças de desempenho em leitura e escrita de alunos da $2^{\mathrm{a}}, 3^{\mathrm{a}}$ e $4^{\mathrm{a}}$ séries do ensino fundamental. Participaram da pesquisa 36 alunos de escolas públicas de Curitiba/PR: 18 crianças com dificuldades de aprendizagem da leitura e da escrita (grupo 1) e outras 18 sem dificuldades de aprendizagem (grupo 2). Os instrumentos de coleta de dados avaliaram: a variação lingüística; a consciência morfossintática e o desempenho das crianças em provas de leitura e ditado. Tinha-se como hipótese que a consciência morfossintática se correlaciona positivamente com o desempenho em leitura e escrita, enquanto a variação lingüística se correlaciona negativamente. Essa hipótese foi confirmada. Destaca-se, entretanto, que $72,15 \%$ das formas lingüísticas não-padrão utilizadas pelos alunos do grupo 1 são empregadas pela maioria dos falantes do português brasileiro, portanto, são formas não-estigmatizadas. Infere-se que a utilização dessas formas lingüísticas pode estar dificultando a escrita correta por parte dessas crianças. Sugere-se que os professores aproveitem os episódios de variação lingüística para levar os alunos a refletir sobre os aspectos morfossintáticos da língua, garantindo-lhes uma capacidade de expressão, oral e escrita, cada vez mais adequada e competente.
\end{abstract}

Palavras-chave: desempenho em leitura e escrita; variação lingüística; consciência morfossintática.

\section{ABSTRACT \\ The influence of linguistic variation and morphological/syntactic awareness on reading and writing performance}

The aim of this study was to investigate the influence of linguistic variation and morphological/ syntactic awareness on the different reading and writing performance levels shown by $1^{\text {st }}-, 2^{\text {nd }}-$ and $3^{\text {rd }}$-grade elementary-school students. The work included 36 students from public schools in Curitiba, PR: 18 children with reading and writing learning problems (Group 1), and another 18 children presenting no difficulties in that respect. The data-collection tools evaluated the following: linguistic variation; morphological/syntactic awareness; and the children's performance in dictation and reading tests. The starting hypothesis was that the morphological/syntactic awareness relates positively to reading and writing performance, while the linguistic variation relates to it negatively. That hypothesis was confirmed. It should be pointed out, however, that $72.15 \%$ of the non-standard linguistic forms used by the students in Group 1 are commonly adopted by most Brazilian-Portuguese speakers, so they must be considered as non-stigmatized forms. It can thus be inferred that the use of these linguistic forms may be making proper writing difficult for these children. It is suggested that teachers should take advantage of linguistic-variation episodes in order to lead students toward reflecting on the morphological-syntactic aspects of the language, so as to assure them of a written and oral ability to express themselves in an increasingly proper and competent way.

Keywords: reading and writing performance; linguistic variation; awareness morphological/syntactic.

\section{INTRODUÇÃO}

No curso da evolução das concepções relativas às dificuldades de aprendizagem em leitura e escrita, identificam-se diferentes hipóteses explicativas. Bryant e Bradley (1987) relatam que muitos déficits já foram sugeridos, ou seja, inicialmente sustentava-se que um "leitor fraco" ou "mau leitor" não via ou es- 
cutava de forma apropriada, mas com o passar dos anos essas explicações têm mudado.

A partir dos anos 70, diversos estudos mostraram que as habilidades metalingüísticas ${ }^{1}$ parecem primordiais na aquisição da leitura e da escrita e revelam-se associadas a maior ou menor eficácia dessa aquisição. Com efeito, o domínio pleno da leitura e da escrita exige conhecimentos claros de diversos aspectos da linguagem e supõe uma tomada de consciência de suas características formais (p. ex.: estrutura fonêmica, estrutura sintática).

Nesse sentido, um grande número de estudos tem evidenciado uma relação estreita entre a aquisição do sistema de escrita e a consciência metalingüística dos constituintes fonológicos das palavras, a chamada "consciência fonológica" (Bradley \& Bryant, 1983; Juel, Griffith \& Gough, 1986; Maluf \& Barrera, 1997; Morais, Alegria \& Content, 1987; Olofsson \& Lundberg, 1985; Wimmer, Landerl, Linortner \& Hummer, 1991; Yopp, 1988). Esses autores defendem que a consciência fonológica é necessária para a aprendizagem da linguagem escrita nas línguas alfabéticas como o francês, inglês ou o português, pois seus sistemas de escrita envolvem a análise das palavras em unidades fonológicas mínimas, os fonemas, os quais são representados pelas letras. O que não significa que a escrita limite-se a uma transcrição fonêmica (nem fonética), mesmo porque não se verifica nos sistemas de escrita uma correspondência biunívoca e recíproca entre letra e som.

$\mathrm{Na}$ realidade, como salientam Marec-Breton e Gombert (2004), a escrita combina dois princípios indispensáveis para sua existência e funcionamento. $\mathrm{O}$ primeiro é fonográfico e diz respeito à relação entre unidades sonoras ou fonemas $(/ \mathrm{p} / \mathrm{a} / \mathrm{t} / \mathrm{o} /)$ e unidades gráficas ou grafemas (p-a-t-o).

O segundo princípio é semiográfico e permite que unidades gráficas (casa) correspondam também a um significado (casa $=$ edifício de moradia). Os morfemas são os menores signos lingüísticos que encerram um significado: se a palavra "casa" for reduzida a "cas", o significado desaparece, pois em português /cas/ não significa nada. Os morfemas podem constituir palavras inteiras (por exemplo, o substantivo casa) ou uma parte da palavra, portadora de significado (por exemplo, o " $s$ " na palavra casas, significando mais de um). Assim, é importante destacar que um signo lingüístico pode ter extensão variável, desde a menor delas, que é justamente o morfema, até a palavra, a frase, o texto etc. A sintaxe estuda tudo o que se relaciona com a combinação linear das palavras nas frases. Desse modo, a consciência morfossintática diz respeito à capacidade que o sujeito possui de fazer considerações, de modo consciente, sobre as palavras enquanto categorias gramaticais e sua posição na frase (considerações sintáticas) e a flexão e a derivação das palavras (considerações morfológicas).

Dado que o sistema ortográfico representa simultaneamente os níveis fonológico e morfossintático, sugere-se que a aprendizagem da leitura e da escrita é influenciada tanto pela consciência fonológica - que possibilita a aquisição das correspondências fonemagrafema - ligada ao processo de decodificação e codificação quanto pela consciência morfossintática - que possibilita a focalização das palavras enquanto categorias gramaticais e a sua adequada posição na construção das frases, aumentando a capacidade de identificação e produção da linguagem escrita. A importância da consideração de aspectos morfossintáticos para a produção de grafias pode ser verificada no seguinte exemplo: quando utilizam a terceira pessoa do singular do pretérito perfeito, muitos falantes do português brasileiro dizem /falô/ para "falou", não pronunciando o "u" final. Portanto, um sujeito que usa como estratégia para produzir grafias a representação dos sons das palavras, tem uma alta probabilidade de produzir grafias erradas.

Um dos principais estudos que dá suporte a esta idéia foi produzido por Tunmer (1990), o qual demonstrou que a consciência sintática é essencial no reconhecimento de palavras. Segundo o referido autor, as crianças utilizam seus conhecimentos sintáticos para dissimular o fracasso da análise fonológica de palavras não familiares (por exemplo, "boxe") ou de palavras homógrafas (por exemplo, "sede" com suas duas pronúncias).

Outros estudos defendem a importância da consideração dos aspectos morfossintáticos para a produção de grafias, entre os quais destaca-se o que foi realizado por Nunes, Bryant e Bindman (1995), que investigaram crianças inglesas na faixa etária de 6 a 11 anos quanto aos processos envolvidos no aperfeiçoamento da ortografia após a primeira série. De acordo com esses autores, seus resultados indicam a possibilidade de que a tomada de consciência de aspectos morfossintáticos da língua constituam uma explicação para o desenvolvimento ortográfico. Nessa mesma perspectiva, um estudo longitudinal realizado por Carlisle (1995) sobre o desenvolvimento metalingüístico em crianças no início da escolarização formal verificou uma relação significativa entre a consciência morfológica e a aquisição de habilidades em leitura. Ou seja, seus resultados apontam que o desempenho das crianças de primeira série nas tarefas morfológicas constitui-se como preditor do desenvolvimento da capacida- 
de de leitura dessas crianças. No entanto, esse mesmo autor indica a necessidade de novos estudos para que se possa concluir sobre a relação de causa-efeito entre o desenvolvimento da leitura e da escrita e o desenvolvimento da consciência morfossintática.

De outra parte, é importante salientar que a representação do significado na escrita - em um sistema alfabético - utiliza a mediação da fala, pois representa o significante verbal a ele associado. Em outras palavras, a escrita alfabética é uma representação direta dos significantes verbais (seqüências de sons que compõem as palavras), representando apenas indiretamente os significados. Desse modo, a fim de compreender o funcionamento da escrita, é necessário que a criança seja capaz de diferenciar entre significante e significado, reconhecendo o caráter arbitrário da relação entre eles.

Kato (1987) explica que embora a escrita alfabética tenha sido criada com o objetivo de representar a fala, ela não possui uma natureza estritamente fonética, pois apresenta várias irregularidades nas relações entre letras e fonemas por determinações etimológicas relativas a aspectos históricos e/ou relacionados ao sistema lexical da língua. Acrescenta ainda que, ao se tentar compreender a escrita como representação da fala, deve-se levar em conta que a linguagem oral é dinâmica, modificando-se de acordo com o tempo, o lugar, a cultura e a classe social dos falantes - o que dá origem às chamadas variações dialetais -, enquanto que a língua escrita é mais estável e presa a convenções gramaticais. Assim, tem-se como resultado o distanciamento entre esses dois sistemas de linguagem.

Entretanto, deve-se considerar que existe uma influência recíproca entre esses dois sistemas, pois se a escrita alfabética surge com a intenção de representar a fala natural, "pré-letramento", logo em seguida ela passa a se desenvolver de uma maneira praticamente autônoma, por meio da utilização de convenções rígidas (gramaticais) que passam a influenciar a própria fala, resultando na fala "pós-letramento". Nessa perspectiva, a "fala padrão" nada mais é do que a simulação da própria escrita (Kato, 1987).

Assim, dentre as variedades lingüísticas ${ }^{2}$ existentes, a língua padrão é quase sempre a forma escolhida para a escrita, com raras exceções, como as cartas familiares ou a literatura popular (cordel, por exemplo).

A língua escrita (padrão) atua, portanto, como fator de unificação lingüística, pois representa todas as variedades de uma determinada língua. Na opinião de Pretti (1994), a língua padrão "serve diretamente às intenções do ensino no sentido de padronizar a língua, criando condições ideais de comunicação entre as várias áreas geográficas e também propiciando aos estudantes condições para a leitura e compreensão dos textos literários e científicos, que se expressam nessa linguagem" (p. 31).

Destaca-se, então, que um dos principais objetivos da escola é divulgar a língua padrão, de modo a ser apropriada pelos alunos à medida que elevam seu grau de instrução. Além disso, a escola tem a tarefa de propiciar o contato sistemático com a modalidade escrita (baseada na tradição gramatical normativa), para que eles possam apropriar-se da linguagem escrita de modo cada vez mais adequado e competente.

Por essa razão, considera-se imprescindível que os professores (principalmente os alfabetizadores) tenham acesso a conhecimentos lingüísticos - bem como psicolingüísticos e sociolingüísticos - que lhes permitam fundamentar criticamente sua prática pedagógica.

Entre esses conhecimentos, vários autores (Gnerre \& Cagliari, 1985; Nunes, 1993; Zorzi, 1998) destacam a necessidade do professor compreender que a alfabetização tem origem na descoberta do aluno de que as letras representam os sons da fala, entretanto o domínio da escrita requer que ele reformule essa compreensão, se dando conta de que em algumas situações não existe uma correspondência regular entre letra e som. Ou seja, o aperfeiçoamento da concepção alfabética exige do aluno a compreensão de que a correspondência entre língua falada e língua escrita é indireta e muitas vezes irregular.

Por último, focalizando a relação entre linguagem e alfabetização, Franchi (1988) aponta que além das dificuldades do sistema gráfico da língua portuguesa comuns a todos os falantes da norma padrão (devidas às determinações etimológicas relativas a aspectos históricos e/ou relacionados ao sistema lexical da língua), os falantes de outras variedades da língua apresentam dificuldades ortográficas especiais, decorrentes da distância entre sua variedade lingüística e a grafia.

A partir dessas considerações depreende-se a importância do presente estudo, que teve como objetivo central investigar a influência dos níveis de variação lingüística e de consciência morfossintática nas diferenças de desempenho em leitura e escrita de alunos da $2^{\mathrm{a}}, 3^{\mathrm{a}}$ e $4^{\mathrm{a}}$ séries do ensino fundamental.

A princípio, as hipóteses de trabalho propostas pela pesquisadora foram as seguintes:

- Os níveis de variação lingüística tendem a se correlacionar negativamente com os desempenhos em leitura e escrita, enquanto que a cons- 
ciência morfossintática se correlaciona positivamente.

- Em geral, os sujeitos que apresentam menores índices de variação linguíística apresentam, inversamente, escores mais elevados nas tarefas que avaliam a consciência morfossintática.

\section{METODOLOGIA}

\section{Sujeitos Participantes}

O universo da pesquisa é formado por alunos da $2^{\mathrm{a}}$, $3^{\mathrm{a}}$ e $4^{\mathrm{a}}$ séries do Ensino Fundamental de Escolas Públicas do Município de Curitiba - Núcleo Regional do Pinheiro - que possuem salas de recursos ${ }^{3}$.

Do referido universo (que abrange oito instituições escolares), foram escolhidas aleatoriamente duas escolas. Após obter o consentimento dos responsáveis pelas instituições para a realização da investigação científica pretendida, a pesquisadora aplicou o Teste de Desempenho Escolar-TDE (Stein, 1994) aos alunos das salas de recursos, indicados pelos professores como tendo fraco desempenho em leitura e escrita. Com base nos resultados do TDE, foram selecionados 18 alunos, os quais compuseram o grupo 1. Emparelhado a este, foi formado um outro grupo, inicialmente com 18 alunos, que por motivo de transferência de um deles ficou restrito a 17. Assim, participaram da pesquisa dois grupos de alunos, a saber:

- Grupo 1 - composto por 18 alunos (quatro da $3^{\mathrm{a}}$ série e quatorze da $4^{\mathrm{a}}$ série), com idade variando de 10 a 13 anos e 6 meses (média 11 anos e 8 meses), que apresentavam dificuldades em leitura e escrita e freqüentavam, além das aulas regulares, salas de recursos.

- Grupo 2 - composto por 17 alunos (três de $2^{\mathrm{a}}$ série e quatorze da $3^{\text {a }}$ série), com idade variando de 6 anos e 3 meses a 7 anos e 10 meses (média 8 anos e 7 meses), sem dificuldades em leitura e escrita, que freqüentavam apenas as aulas regulares. Os sujeitos desse grupo foram selecionados emparelhando-se, a cada um dos sujeitos do grupo 1 , um sujeito da série anterior, por indicação aleatória das professoras. Destaca-se que os alunos do grupo 2 apresentavam uma média de idade inferior à dos alunos do primeiro grupo.

De acordo com os dados fornecidos pelas equipes pedagógico-administrativas das escolas, os alunos são oriundos de famílias com renda familiar de dois a cinco salários mínimos. Além disso, a escolaridade média de seus pais é a de ensino fundamental. Com base nesses dados, considerou-se que não havia variação socioeconômica significativa entre os sujeitos pesquisados.

\section{Material e Procedimento}

O presente estudo foi baseado em três tipos de instrumentos de coleta de dados:

1. Tarefas de leitura (reconhecimento de palavras e compreensão) e de escrita (ditado).

\subsection{Reconhecimento de palavras (decodificação) e compreensão da leitura}

\section{A) Reconhecimento de palavras (decodificação)}

Essa prova consiste na leitura de 70 palavras apresentadas isoladamente, pertencentes ao Subteste de Leitura do TDE - Teste de Desempenho Escolar (Stein, 1994).

\section{B) Compreensão da leitura}

Para avaliação da compreensão da leitura foi empregada a técnica de Cloze ${ }^{4}$ no texto "O pulo do gato". O texto de Cloze foi preparado usando como parâmetro a omissão sistemática de palavras num sistema de razão, ou seja, foi omitido todo $8^{\circ}$ vocábulo.

É importante salientar que essa técnica foi empregada com base no estudo de Santos (2004, p. 224), que verificou a possibilidade de sua utilização para "avaliação das dificuldades de compreensão dos alunos."

\subsection{Ditado}

A tarefa de escrita (ortografia) foi realizada a partir do ditado do texto da escala Avaliação na Aprendizagem da Escrita (Adape) - instrumento construído e validado por Sisto (2001).

O texto da escala é constituído por 114 palavras (60 apresentando dificuldades que envolvem encontros consonantais, dígrafos, sílabas compostas e sílabas complexas).

\section{Tarefa de avaliação da variação lingüística}

Para avaliar o nível de variação lingüística dos alunos, foi utilizado o mesmo instrumento empregado por Barrera (2000). Esse instrumento é a história em quadrinhos intitulada "Pega-ladrão", do livro infantil "A bruxinha atrapalhada" (Furnari, 1993). Essa obra apresenta várias histórias, compostas apenas por ilus- 
trações, possibilitando às crianças construírem oralmente seu próprio texto, a partir das figuras.

As verbalizações das crianças foram gravadas em áudio e posteriormente transcritas, para que se pudesse verificar o percentual de formas lingüísticas nãopadrão utilizadas.

\section{Tarefas de avaliação da consciência morfossintática}

Para avaliar a consciência morfológica e sintática, foram aplicados três tipos de tarefas, nas quais as crianças deveriam gerar determinadas palavras (tarefas 3.1 e 3.2) ou corrigir a anomalia morfêmica de algumas palavras apresentadas no contexto de uma sentença (tarefa 3.3).

As duas primeiras tarefas foram desenvolvidas usando-se como referência as tarefas utilizadas no estudo de Nunes, Bryant e Bindman (1996) com crianças falantes do inglês. A terceira é semelhante às tarefas que foram utilizadas por Bowey (1986) com crianças falantes do inglês e, mais tarde, por Demont (1997) com crianças falantes do francês.

As três tarefas foram realizadas oralmente e apresentadas individualmente às crianças.

\subsection{Tarefa de uso gerativo de morfemas}

Esta tarefa requer que as crianças flexionem formas verbais apresentadas no contexto de duas ou três sentenças. Os itens foram elaborados tomando como referência uma das situações apresentadas a seguir:

- pronúncia ou omissão do "r" nos infinitivos verbais (p. ex.: pronunciar/passear/ ou /passiá/, /cantar/ ou /cantá/, /comprar/ ou /comprá/);

- pronúncia ou omissão do "u" final em verbos no pretérito perfeito, terceira pessoa do singular (p. ex.: pronunciar /dançou/ ou /dançô/, /falou/ ou /falô/, /mostrou/ ou /mostrô/);

- pronúncia ou omissão do "s" final em verbos no pretérito perfeito, primeira pessoa do plural (p. ex.: pronunciar /compramos/ ou /compramo/, /perdemos/ ou /perdemo/, /brincamos/ ou /brincamo/);

- pronúncia ou omissão da nasalização do ditongo nasal átono em verbos no pretérito, terceira pessoa do plural (p. ex.: pronunciar /cantaram/ ou /cantaro/, /deram/ ou /deru/).

Antes do início da tarefa propriamente dita, a criança fazia um treino: ela ouvia duas ou três frases que

Interação em Psicologia, Curitiba, jul./dez. 2005, (9)2, p. 261-271 introduziam o verbo que ela deveria conjugar e, na seqüência, a frase que ela deveria completar.

Nesta tarefa, foram utilizados 14 itens (2 para treino e 12 para exame), conforme os exemplos a seguir:

1) Hoje pela manhã arrumei o meu quarto inteirinho. Quando minha mãe viu, me disse: - Muito bem, você arrumou tudo sem precisar que eu pedisse para você

2) Minhas primas Joana e Rafaela adoram dançar. Sábado passado, no baile da primavera, elas dançaram muito, mas Joana foi a que mais

\subsection{Tarefa de analogias morfológicas}

Esta tarefa foi montada conforme o esquema tradicionalmente utilizado em tarefas de analogias, ou seja, "A" está para "B" assim como "C" está para "D". Portanto, essa tarefa consiste em apresentar, inicialmente, os dois primeiros elementos; a seguir, apresenta-se o terceiro elemento, "C", e o sujeito deve produzir o quarto elemento. As palavras do primeiro par, "A" e "B", têm a mesma raiz mas pertencem a categorias gramaticais distintas. $\mathrm{O}$ primeiro elemento de cada um dos pares ("A" e "C") pertence à mesma categoria mas têm radicais distintos. Para responder à tarefa, as crianças deveriam utilizar o radical de " $\mathrm{C}$ " e gerar uma palavra da mesma categoria gramatical de " $\mathrm{B}$ ".

A tarefa é composta por 14 itens (dois de treino e doze de exame) e envolve relações entre elementos das seguintes categorias gramaticais: substantivo $\rightarrow$ verbo (itens 1 e 7 ); verbo $\rightarrow$ substantivo (itens $4 \mathrm{e}$ 10 ); adjetivo $\rightarrow$ verbo (itens 2 e 8 ); verbo $\rightarrow$ adjetivo (itens 5 e 11); substantivo $\rightarrow$ adjetivo (itens 3 e 9); adjetivo $\rightarrow$ substantivo (itens 6 e 12).

Os itens 1 e 2 são apresentados como exemplo:
1) A - estudo
B - estudar
$\mathrm{C}-$ abraço
D -
2) A - rasgado
B - rasgar
$\mathrm{C}$ - furado
$\mathrm{D}$ -

\subsection{Tarefa de correção das violações gramaticais contidas nas frases}

Nesta tarefa as crianças deveriam corrigir uma série de frases gramaticalmente incorretas, englobando concordância verbal, emprego de pronomes, flexões de substantivos e adjetivos. Destaca-se que, em cada uma das frases, apenas uma palavra estava incorreta, 
estando envolvidas anomalias morfêmicas como, por exemplo, "Nós vai ao circo no próximo domingo", "Marta veste sua casaco", "Juliana tem lindas olhos".

Ao todo foram apresentados quatorze itens para correção ( 2 de treino e 12 de exame).

\section{RESULTADOS}

Como o número de acertos podia variar de acordo com as diferentes tarefas utilizadas neste estudo, todos os resultados serão apresentados em porcentagem. Além disso, destaca-se que os dados obtidos foram submetidos a provas estatísticas, porém, como os gru- pos eram pequenos e a maioria dos instrumentos utilizados não era testes padronizados para a população em geral, optou-se pelo uso de testes estatísticos nãoparamétricos (Siegel, 1975).

\section{Leitura e escrita}

A Tabela 1 mostra a média e desvio-padrão da idade cronológica dos 35 sujeitos que participaram da pesquisa, bem como a média com o respectivo desviopadrão dos escores obtidos nas tarefas de decodificação, compreensão da leitura e escrita.

Tabela 1. Média e desvio-padrão da idade cronológica e dos percentuais de acertos nas tarefas de leitura e de escrita, por grupo

\begin{tabular}{|c|c|c|c|c|c|c|c|c|c|}
\hline \multirow{3}{*}{ GRUPO } & \multirow{3}{*}{$\mathrm{N}$} & \multicolumn{2}{|c|}{ Idade } & \multicolumn{4}{|c|}{ Leitura } & \multicolumn{2}{|c|}{ Escrita } \\
\hline & & \multirow[b]{2}{*}{ M. } & \multirow[b]{2}{*}{ D.P. } & \multicolumn{2}{|c|}{ Decodificação } & \multicolumn{2}{|c|}{ Compreensão } & \multirow[b]{2}{*}{ M. } & \multirow[b]{2}{*}{ D.P. } \\
\hline & & & & M. & D.P. & M. & D.P. & & \\
\hline Grupo 1 & 18 & 11a. $8 \mathrm{~m}$. & $10 m$ & 72,06 & 18,97 & 52,22 & 17,88 & 55,70 & 16,51 \\
\hline Grupo 2 & 17 & $8 \mathrm{a} .7 \mathrm{~m}$. & $6 m$. & 93,45 & 5,89 & 80,00 & 12,47 & 76,42 & 9,87 \\
\hline Total & 35 & 10a. $2 \mathrm{~m}$. & $1 a .8 m$. & 82,45 & 17,75 & 65,71 & 9,55 & 65,76 & 17,10 \\
\hline
\end{tabular}

Como se pode observar na Tabela 1 , tanto nas tarefas de leitura (decodificação e compreensão) como na de escrita (ditado), os sujeitos do grupo 1 tiveram desempenho abaixo do desempenho dos outros sujeitos.

A comparação das médias nas três tarefas utilizando a Prova U de Mann-Whitney mostrou que as diferenças entre os grupos são significativas. Ou seja, para a tarefa de decodificação verificou-se $(\mathrm{U}=23,50$; $\mathrm{p}<0,001)$, para a tarefa de compreensão da leitura $(\mathrm{U}=17,50 ; \mathrm{p}<0,001)$ e para a tarefa de escrita $(\mathrm{U}=$ 47,00; $\mathrm{p}<0,001)$.

Analisando-se o desempenho dos sujeitos do grupo 1 nas duas tarefas de leitura, verificou-se que, em média, eles conseguiram decodificar mais de $70 \%$ das palavras apresentadas, o que indica claramente a sua compreensão do princípio alfabético. De outra parte, na tarefa de compreensão da leitura obtiveram uma média de 52,22\%. Portanto, infere-se que esses alunos, apesar de razoáveis decodificadores, não conseguem ler com presteza um número considerável de palavras para formar um texto significativo.
No que se refere à tarefa de escrita, evidenciou-se que os erros ortográficos dos sujeitos do grupo 1 envolvem tanto palavras que apresentam uma relação biunívoca entre letras e sons (regulares) quanto aquelas que não apresentam tal relação (regra e irregulares). Tendo em vista esses resultados, conclui-se que os erros cometidos têm sua origem em problemas relacionados com a análise fonológica das palavras, com a análise do contexto ortográfico, bem como com a análise morfossintática.

\section{Variação lingüística}

Para avaliar o nível de variação lingüística dos sujeitos foi calculado o percentual de formas lingüísticas não-padrão empregadas na construção do texto oral. Na Tabela 2 são mostrados o escore máximo, o mínimo, a média e o desvio-padrão da variação lingüística de cada um dos grupos.

Tabela 2. Escores obtidos na tarefa de avaliação da variação lingüística, por grupo

\begin{tabular}{cccccc}
\hline & & \multicolumn{4}{c}{ Variação lingüística } \\
\cline { 3 - 6 } Grupo & $\mathrm{N}$ & E. Min. & E. Max. & M. & D.P. \\
\hline 1 & 18 & 13,38 & 52,75 & 26,26 & 11,17 \\
2 & 17 & 6,16 & 50,00 & 18,48 & 10,00 \\
\hline Total & 35 & & & 22,48 & 11,18 \\
\hline
\end{tabular}


O exame dos resultados permite afirmar que, como se esperava, os sujeitos do grupo 1 apresentam um nível de variação lingüística superior ao dos sujeitos do grupo 2. A comparação das médias (Prova U de Mann-Whitney) mostrou que a diferença entre os grupos é significativa $(\mathrm{U}=81,00 ; \mathrm{p}=0,017)$.
A análise das diferentes variações lingüísticas identificadas nos dois grupos de sujeitos permitiu a classificação dessas variações em 18 categorias, como pode ser observado no Tabela 3. Outrossim, destacase que ocorreram algumas variações que não foram enquadradas em nenhuma categoria e, por isso, foram agrupadas e classificadas como "outras variações".

Tabela 3. Categorias empregadas na classificação das variações lingüísticas identificadas

\begin{tabular}{|c|c|c|c|c|c|}
\hline \multirow[t]{2}{*}{ Categorias } & \multirow[t]{2}{*}{ Tipos de variação lingüística } & \multicolumn{2}{|c|}{$\begin{array}{l}\text { Variações lingüísticas } \\
\text { identificadas no G1 }\end{array}$} & \multicolumn{2}{|c|}{$\begin{array}{l}\text { Variações lingüísticas } \\
\text { identificadas no G2 }\end{array}$} \\
\hline & & $\mathrm{F}$ & $\%$ & $\mathrm{~F}$ & $\%$ \\
\hline 1. Pronúncia das vogais [e] e [o] como [i] e [u] & alegri, mininu etc. & 476 & $40,64 \%$ & 226 & $33,38 \%$ \\
\hline 2. Omissão do [r] nos infinitivos verbais & brincá, passeá etc. & 94 & $8,02 \%$ & 65 & $9,60 \%$ \\
\hline $\begin{array}{l}\text { 3. Omissão do [u] final (verbos no pretérito } \\
\text { perfeito, } 3^{\underline{a}} \text { pessoa singular) }\end{array}$ & falô, mostrô etc. & 198 & $16,91 \%$ & 171 & $25,26 \%$ \\
\hline $\begin{array}{l}\text { 4. Omissão da nasalização do ditongo nasal } \\
\text { átono (verbos no pretérito, } 3^{\mathrm{a}} \text { pessoa plu- } \\
\text { ral) }\end{array}$ & $\begin{array}{l}\text { saíro, fizero, brigaro, ficaro/u, } \\
\text { pegaro etc. }\end{array}$ & 5 & $0,43 \%$ & - & - \\
\hline $\begin{array}{l}\text { 5. Redução do [n] do grupo consonantal [nd] } \\
\text { no gerúndio }\end{array}$ & $\begin{array}{l}\text { pensano, chorano, sorrinu, } \\
\text { correnu etc. }\end{array}$ & 62 & $5,29 \%$ & 14 & $2,07 \%$ \\
\hline 6. Redução dos ditongos [ei], [ai], e [ou] & caxa, dexa, ôtro etc. & 20 & $1,71 \%$ & 21 & $3,10 \%$ \\
\hline 7. Expansão de monotongos em ditongos & feiz, deiz, tambeim etc. & 57 & $4,87 \%$ & 59 & $8,71 \%$ \\
\hline $\begin{array}{l}\text { 8. Contrações, aglutinações e outras varia- } \\
\text { ções relacionadas aos aspectos prosódicos } \\
\text { do ritmo geral da fala }\end{array}$ & $\begin{array}{l}\text { ca/cas (com a/as), cê (você), } \\
\text { ni (em) etc. }\end{array}$ & 152 & $12,98 \%$ & 85 & $12,56 \%$ \\
\hline 9. Prótese de um [a] em formas verbais & atropeço, avoar etc. & 5 & $0,43 \%$ & 7 & $1,03 \%$ \\
\hline 10. Prócope de um [a] em algumas palavras & dimirado, sustô etc. & 3 & $0,26 \%$ & 3 & $0,44 \%$ \\
\hline 11. Substituiç̧ão de [lh] por [i] & óia, trabaia, muié etc. & 4 & $0,34 \%$ & 2 & $0,30 \%$ \\
\hline 12. Substituição de [l] por [r] & craru, bicicreta etc. & - & - & 1 & $0,15 \%$ \\
\hline 13. Terminação nasal [em] pronunciada como [i] & homi, onti etc. & 24 & $2,05 \%$ & - & - \\
\hline 14. Omissão de [r] em grupos consonantais & pá (pra), ôto (outro) etc. & 24 & $2,05 \%$ & 9 & $1,33 \%$ \\
\hline 15. Ausência de concordância nominal & dois gol, os aluno etc. & 8 & $0,68 \%$ & 2 & $0,30 \%$ \\
\hline 16. Ausência de concordância verbal & as pessoa gosta etc. & 3 & $0,26 \%$ & 3 & $0,44 \%$ \\
\hline 17. Variações lexicais (de vocabulário) & tacá (jogar), coisá etc. & 11 & $0,94 \%$ & 3 & $0,44 \%$ \\
\hline 18. Variação envolvendo flexão de adjetivo & mais melhor etc. & 1 & $0,09 \%$ & - & - \\
\hline 19. Outras variações & ingual, tamém etc. & 24 & $2,05 \%$ & 6 & $0,89 \%$ \\
\hline TOTAL & & 1171 & $100 \%$ & 677 & $100 \%$ \\
\hline
\end{tabular}

A análise dos percentuais de variação lingüística dos sujeitos do grupo 1 permite a constatação de que $72,15 \%$ das formas lingüísticas não-padrão utilizadas pelos sujeitos do grupo 1 são relativas às categorias 1 , $2,3,6$ e 7, que dizem respeito às variações empregadas pela maioria dos falantes do português brasileiro.

Entretanto, embora não estigmatizadas, essas formas lingüísticas não-padrão empregadas pelo grupo 1 parecem estar dificultando a escrita ortograficamente correta desses sujeitos, na medida em que eles se apóiam na oralidade para escrever, ou seja, ao escreverem fazem uma transcrição da fala. Destaca-se que o domínio da linguagem escrita por parte dos sujeitos falantes de variantes dialetais afastadas da norma padrão implica a necessidade de domínio/memorização de um número maior de irregularidades na correspondência fala/escrita. 


\section{Consciência morfossintática}

A Tabela 4 sumariza os resultados obtidos nas três tarefas de consciência morfossintática. Esses resultados indicam que em todas as tarefas o desempenho do grupo 1 foi menor do que o desempenho do grupo 2 . Além disso, foi realizada uma análise de correlação que mostrou a existência de uma correlação positiva entre as três tarefas. Portanto, definiu-se um escore único de consciência morfossintática a partir da média dos escores percentuais obtidos nas três tarefas (uso gerativo de morfemas, analogias morfológicas e correção das violações gramaticais contidas nas frases).

Tabela 4. Média dos percentuais de acertos nas três tarefas de consciência morfossintática e escore único de consciência morfossintática

\begin{tabular}{|c|c|c|c|c|c|c|}
\hline \multirow[b]{2}{*}{ Grupo } & \multirow[b]{2}{*}{$\mathrm{N}$} & \multicolumn{3}{|c|}{ Médias percentuais das tarefas de consciência morfossintática } & \multicolumn{2}{|c|}{$\begin{array}{l}\text { Escore de consciência } \\
\text { morfossintática }\end{array}$} \\
\hline & & $\begin{array}{l}\text { Uso gerativo de } \\
\text { morfemas }\end{array}$ & $\begin{array}{c}\text { Analogias } \\
\text { morfológicas }\end{array}$ & $\begin{array}{l}\text { Correção das } \\
\text { violações } \\
\text { gramaticais }\end{array}$ & M. & D.P. \\
\hline 1 & 18 & 71,76 & 55,56 & 69,91 & 65,74 & 15,86 \\
\hline 2 & 17 & 93,14 & 66,18 & 90,69 & 83,33 & 8,95 \\
\hline Total & 35 & 82,14 & 60,71 & 79,10 & 74,29 & 15,59 \\
\hline
\end{tabular}

A comparação das médias dos dois grupos nos escores de consciência morfossintática por meio da Prova U de Mann-Whitney mostrou que a diferença entre os grupos é significativa $(U=54,50 ; p=0,001)$.

Outrossim, vale salientar que os dois grupos apresentaram menor média de desempenho na tarefa de analogias morfológicas quando comparada com a média nas outras tarefas de consciência morfossintática, embora o grupo 1 tenha apresentado a média mais baixa $(55,56 \%)$. Considerando esse resultado, pode-se dizer que essa foi a tarefa de maior complexidade para os alunos, provavelmente porque eles não são orientados a refletir sobre "família lexical" e, por isso, apresentaram dificuldade para gerar palavras que pertencem à mesma "família".

Em relação à tarefa de correção das violações gramaticais, a análise do desempenho dos sujeitos do grupo 1 mostrou que algumas das frases dessa tarefa lhes pareciam corretas, justamente por eles serem falantes de dialetos orais afastados da norma culta/padrão e, provavelmente, carecerem de uma reflexão que possibilitasse o desenvolvimento da capacidade de compreender diferentes tipos de discurso.

\section{DISCUSSÃO}

Existe expressivo suporte empírico e teórico para a afirmação de que nas línguas alfabéticas a consciência fonológica exerce papel fundamental na aprendizagem da leitura e da escrita. Paralelamente, vários autores têm demonstrado que a consciência morfossintática também contribui para o desenvolvimento da linguagem escrita. Além disso, dado que a escrita alfabética representa os significantes verbais, embora ela não possua uma natureza estritamente fonética, é necessário considerar que existe uma influência recíproca entre a fala e a escrita. Porém, evidencia-se ainda que, dentre as variedades lingüísticas existentes, a língua padrão é quase sempre a forma escolhida para a escrita.

Assim, formulou-se a hipótese de que os níveis de variação lingüística tendem a se correlacionar negativamente com os desempenhos em leitura e escrita, enquanto que a consciência morfossintática se correlaciona positivamente.

Analisando-se os resultados obtidos neste estudo, pode-se dizer que essa hipótese foi confirmada. Por um lado, a prova de correlação de Spearman mostrou que os índices de variação lingüística correlacionamse negativa e significativamente com o desempenho nas tarefas de decodificação $\left(r_{s}=-0,428 ; p=0,01^{*}\right)$; compreensão da leitura $\left(\mathrm{r}_{\mathrm{s}}=-0,516 ; \mathrm{p}=0,002^{* * *}\right)$ e ditado $\left(\mathrm{r}_{\mathrm{s}}=-0,375 ; \mathrm{p}=0,027^{*}\right)$. Esses resultados corroboram a explicação apresentada por Franchi (1988) quando argumenta que os falantes de variedades lingüísticas não-padrão têm dificuldades ortográficas especiais (para além das dificuldades do sistema gráfico da língua portuguesa comum a todos os falantes da norma padrão), causadas pela distância entre sua variedade linguística e a grafia. Nesse sentido, em vários estudos há referências explícitas de que muitos dos erros ortográficos são produzidos devido ao fato dos sujeitos grafarem as palavras apoiando-se no modo de falar (Nunes, 1993; Cagliari, 1997; Zorzi, 1998).

Por outro lado, a prova de correlação de Spearman mostrou que os escores de consciência morfossintática correlacionam-se positiva e significativamente com os desempenhos nas mesmas tarefas de decodificação 
$\left(\mathrm{r}_{\mathrm{s}}=0,68 ; \mathrm{p}<0,001^{* *}\right)$; compreensão da leitura $\left(\mathrm{r}_{\mathrm{s}}=\right.$ 0,$\left.656 ; p<0,001^{* *}\right)$ e ditado $\left(r_{s}=0,648 ;<0,001^{* * *}\right)$. Resultados semelhantes foram encontrados no estudo de Tunmer, Nesdale e Wright (1987), que constataram um efeito causal das dificuldades no nível do domínio sintático sobre o desempenho em leitura. Da mesma forma, Rego e Bryant (1993) mostraram que existe uma relação significativa entre leitura de palavras numa frase e a consciência sintática em crianças no primeiro ano da alfabetização. Acrescenta-se, ainda, que, na investigação de Nunes, Bryant e Bindman (1995), foi observada uma relação significativa entre o uso adequado de morfemas na escrita e a leitura de palavras. Por isso, esses autores sugerem que a utilização de morfemas como unidades significativas seja importante tanto para a escrita como para a leitura, conforme já havia sido apontado por Carlisle (1995), quando verificou que o desempenho de crianças da primeira série em tarefas morfológicas era preditor do desenvolvimento da sua capacidade de leitura.

Nessa perspectiva, acredita-se que os resultados aqui apresentados trazem novas evidências que ilustram como as diferenças de desempenho em leitura e escrita podem estar relacionadas com o desenvolvimento da consciência morfossintática.

É preciso, entretanto, salientar que a outra hipótese desse estudo era de que os sujeitos com menores índices de variação lingüística apresentassem, inversamente, escores mais elevados nas tarefas que avaliavam a consciência morfossintática. Essa hipótese não foi confirmada. A prova de correlação de Spearman mostrou que não existe correlação significativa entre os índices de variação lingüística e os escores de consciência morfossintática $\left(r_{s}=-0,29 ; p=0,089\right)$. A partir desses resultados, pode-se inferir que é possível aos falantes de variantes lingüísticas não-padrão o desenvolvimento da consciência morfossintática que possibilite a eles uma capacidade de expressão escrita adequada. Em outras palavras, infere-se que, pela mediação dos professores e participação em atividades de leitura e escrita, especialmente de textos ${ }^{6}$, os alunos podem desenvolver suas habilidades metalingüísticas e, conseqüentemente, uma maior competência na linguagem escrita.

Esses dados têm interessantes implicações educacionais, pois sugerem que pedagogicamente os episódios de variação lingüística não devem ser desconsiderados ou corrigidos de forma puramente normativa, isto é, tratados como "linguagem errada". Os professores devem aproveitar esses episódios tanto para discutir com os alunos a legitimidade de diferentes variantes lingüísticas como para levá-los a refletir sobre a variedade padrão. Assim, recomenda-se que nas séries iniciais do ensino fundamental sejam desenvolvidas atividades pedagógicas que tenham como objetivo levar os alunos à tomada de consciência dos aspectos formais e estruturais da linguagem oral e sua relação com a escrita. Essas atividades devem propiciar aos alunos o aperfeiçoamento da hipótese de uma correspondência biunívoca entre letras e sons (fonemas), ou seja, a conscientização das irregularidades dessa correspondência que, embora aparentemente arbitrárias, podem ser derivadas do contexto ortográfico, da estrutura morfológica das palavras, ou mesmo da distância da fala do aluno (tanto por fatores regionais quanto sociais) com relação à norma padrão na qual a escrita se baseia.

Enfim, acredita-se que as atividades sugeridas favorecem o desenvolvimento de habilidades metalingüísticas que possibilitam uma reflexão sobre o conhecimento gramatical que o aluno tem internalizado (e lhe permite ser falante de uma determinada variante lingüística), no sentido de facilitar a apropriação da norma padrão, garantindo-lhe um desempenho em leitura e escrita cada vez mais adequado e competente.

\section{REFERÊNCIAS}

Bagno, M. (2001) (Org.). Norma lingüística. São Paulo: Loyola.

Barrera, S. D. (2000). Linguagem oral e alfabetização: um estudo sobre variação lingüística e consciência metalingüística em crianças da $1^{a}$ série do ensino fundamental. Tese de doutorado, Instituto de Psicologia, Universidade de São Paulo, São Paulo.

Bowey, J. A. (1986). Syntactic awareness in relation to reading skill and ongoing reading comprehension monitoring. Journal of Experimental Child Psychology, 41, 282-299.

Bradley, L. \& Bryant, P. E. (1983). Categorizing sounds and learning to read - a causal connection. Nature, 301, 419-421.

Bryant, P. E. \& Bradley, L. (1987). Problemas de aprendizagem de leitura. (I. C. S. Ortiz, Trad.) Porto Alegre: Artes Médicas. (Trabalho original publicado em 1985).

Cagliari, L. C. (1997). Alfabetização \& lingüística (10 a ed.). São Paulo: Scipione.

Carlisle, J. F. (1995). Morphological Awareness and Early Reading Achievement. Em L. B. Feldman (Org.), Morphological aspects of language processing (pp. 189-209). Hillsdale, NJ: LEA.

Curitiba. (1992). Prefeitura Municipal de Curitiba. Secretaria Municipal de Educação. Proposta de Educação Especial na Secretaria Municipal de Educação. Curitiba.

Demont, E. (1997). Consciência fonológica, consciência sintática: que papel (ou papéis) desempenha na aprendizagem eficaz da leitura? Em J. Grégoire \& B. Piérart, Avaliação dos problemas de leitura: Os novos modelos teóricos e suas implicações diagnósticas (pp. 189-201). Porto Alegre: Artes Médicas. Tradução brasileira do original de 1994.

Franchi, E. P. (1988). Pedagogia da alfabetização: da oralidade à escrita. São Paulo: Cortez.

Furnari, E. (1993). A bruxinha atrapalhada. São Paulo: Global. 
Gnerre, M. B. A. \& Cagliari, L. C. (1985). Textos espontâneos na $1^{\mathrm{a}}$ série. Cadernos Cedes - Recuperando a alegria de ler e escrever, 14, 25-29.

Juel, C., Griffith, P. L. \& Gough, P. B. (1986). Acquisition of literacy: A longitudinal study of children in first and second grade. Journal of Educational Psychology, 78 (4), 243-255.

Kato, M. A. (1987). No mundo da escrita: uma perspectiva psicolingüística ( $7^{\mathrm{a}}$ ed.). São Paulo: Ática.

Maluf, M. R. \& Barrera, S. D. (1997). Consciência fonológica e linguagem escrita em pré-escolares. Psicologia: Reflexão $e$ Crítica, 10 (1), 125-145.

Marec-Breton, N. \& Gombert, J. E. (2004). A dimensão morfológica nos principais modelos de aprendizagem da leitura. Em M. R. Maluf (Org.), Psicologia educacional: Questões contemporâneas (pp. 105-121). São Paulo: Casa do Psicólogo.

Morais, J., Alegria, J. \& Content, A. (1987). The relationships between segmental analysis and alphabetic literacy: an interactive view. Cahiers de Psychologie Cognitive, 7(5), 415-438.

Nunes, T. (1993). Leitura e escrita : processos e desenvolvimento. Em E. S. ALENCAR (Org.), Novas contribuições da psicologia aos processos de ensino e aprendizagem ( $2^{\mathrm{a}}$ ed.) (pp. 13-50). São Paulo: Cortez.

Nunes, T., Bryant, P. \& Bindman, M. (1995). E quem se preocupa com a ortografia? Em C. Cardoso-Martins (Org.), Consciência fonológica \& Alfabetização (pp. 129-158). Petrópolis: Vozes.

Olofsson, A. \& Lundberg, I. (1985). Evaluation of long term effects of phonemic awareness training in kindergarten: illustrations of some methodological problems in evaluation research. Scandinavian Journal of Psychology, 26, 21-34.

Preti, D. (1994). Sociolingüística: Os níveis da fala. São Paulo: Edusp.

Rego, L. L. B. \& Bryant, P. E. (1993). The connection between phonological syntactic and semantic skills and children's reading and spelling. European Journal of Psychology of Education, 8 (3), 235-246.
Santos, A. A. A. (2004). O cloze como técnica de diagnóstico e remediação da compreensão em leitura. Interação em psicologia, 8 (2), 217-226.

Siegel, S. (1975). Estatística não-paramétrica para as ciências do comportamento. São Paulo: McGraw-Hill do Brasil. Tradução brasileira do original de 1956.

Sisto, F. F. (2001). Dificuldades de aprendizagem em escrita: um instrumento de avaliação (Adape). Em F. F. Sisto, E. Boruchovitch \& L. D. T. Fini (Orgs.), Dificuldades de aprendizagem no contexto psicopedagógico (pp. 190-213). Petrópolis: Vozes.

Stein, L. M. (1994). TDE: Teste de desempenho escolar: manual para aplicação e interpretação. São Paulo: Casa do Psicólogo.

Tunmer, W. E. (1990). The role of language prediction skills in beginning reading. New Zealand Journal of Educational Studies, 25(2), 95-114.

Tunmer, W. E., Nesdale, A. R. \& Wright, A. D. (1987). Syntactic awareness and reading acquisition. British Journal of Developmental Psychology, 5, 25-34.

Wimmer, H., Landerl, K., Linortner, R. \& Hummer, P. (1991). The relationship of phonemic awareness to reading acquisition: more consequence than precondition but still important. Cognition, 40, 219-249.

Yavas, F. (1988). Habilidades metalingüísticas na criança: uma visão geral. Cadernos de Estudos Lingüísticos, 14, 39-51.

Yopp, H. K. (1988). The validity and reliability of phonemic awareness tests. Reading Research Quarterly, 23(2), 159-177.

Zorzi, J. L. (1998). Aprender a escrever: a apropriação do sistema ortográfico. Porto Alegre: Artes Médicas.

Recebido: 18/09/2005 Revisado: 30/11/2005 Aceito: 05/12/2005

\section{Notas:}

${ }^{1}$ Neste artigo, o termo habilidade metalingüística será utilizado, conforme já apresentado por outros autores (Yavas,1988; Demont, 1997), para designar a capacidade do indivíduo de tratar a linguagem como objeto de análise e reflexão e a capacidade de controlar e planejar seus próprios processos lingüísticos.

${ }^{2}$ No presente trabalho, não será feita uma distinção entre os termos norma padrão, norma culta, variedade padrão e dialeto padrão, que são empregados para designar as variedades lingüísticas de prestígio. A variedade padrão é aquela ensinada na escola e normatizada pelas gramáticas. Variedade não-padrão diz respeito a quaisquer variedades lingüísticas diferentes da variedade padrão. Nesse sentido, o termo variação lingüística refere-se à distância entre a fala do sujeito em relação à norma padrão. Todavia, para uma análise dos problemas terminológicos referentes ao uso das expressões norma culta e norma padrão, confrontar Bagno (2001).

${ }^{3}$ Em relação às salas de recursos, é importante ressaltar que elas "foram implantadas na Rede Municipal de Ensino a partir da necessidade de se oferecer atendimento aos alunos que apresentavam Dificuldades de Aprendizagem (...), cujas características não recomendavam atendimento em Classe Especial." (Curitiba, 1992, p. 50).

${ }^{4}$ Conforme explica Santos (2004), “o Cloze consiste na organização de um texto, do qual se suprimem alguns vocábulos e se pede ao leitor que preencha os espaços com as palavras que melhor completarem o sentido do texto."

${ }^{5}$ Uma "família lexical" é constituída por palavras que provêm do mesmo radical (também chamadas palavras cognatas ou famílias etimológicas). 
* Nível de significância: $p<0,05$.

${ }^{* * *}$ Nível de significância: $p<0,01$.

${ }^{6}$ Acredita-se que os professores, mesmo aqueles das séries iniciais, ao utilizarem o texto como cerne do trabalho pedagógico, enfocam tanto a análise das palavras (relações letra/som, padrões silábicos e morfemas) quanto a análise da própria organização do texto (relação entre palavras, frases, orações, períodos e parágrafos).

\section{Sobre a autora:}

Sandra Regina Kirchner Guimarães: Psicóloga pela PUCPR, Doutora em Psicologia Escolar e do Desenvolvimento Humano pela Universidade de São Paulo. Docente do Curso de Pedagogia e do Programa de Pós-Graduação em Educação Stricto Sensu da Universidade Federal do Paraná.

Endereço para correspondência: Departamento de Teoria e Fundamentos da Educação, Setor de Educação, Universidade Federal do Paraná - Rua General Carneiro, 460 - $4^{\circ}$ andar - 80060-100 - Curitiba - PR (sonnyg@uol.com.br) 